\title{
A study on relationship between emotional maturity and marital satisfaction
}

\author{
Seyed Esmael Mosavi ${ }^{\mathbf{a}^{*}}$ and Mohammad Reza Iravani ${ }^{\mathbf{b}}$
}

${ }^{a}$ Department of Guidance \&Counseling, Islamic Azad University of Khomeinishahr, Khomeinishahr Branch, Daneshjou Blvd, Iran ${ }^{b}$ Department of Social Work, Islamic Azad University of Khomeinishahr, Khomeinishahr Branch, Daneshjou Blvd, Iran

\begin{tabular}{l}
\hline A R T I C L E I N F O \\
\hline Article history: \\
Received July 10, 2011 \\
Received in Revised form \\
October, 12, 2011 \\
Accepted 15 October 2011 \\
Available online \\
22 October 2011 \\
\hline Keywords: \\
Emotional maturity \\
Close character \\
Lack of independence \\
Return emotional \\
Marital satisfaction \\
\end{tabular}
A B S T R A C T

\begin{abstract}
Marriage is one of the most important events of people's lives and when it happens, it could have both positive and negative consequences. In this paper, we present an empirical study to investigate the relationship between emotional maturity and marital satisfaction using a classical questionnaire. The study chooses all people aged 25-35 who live in region 10 of the city of Esfahan, Iran. The proposed study splits the main hypothesis into five detailed questions, which considers the relationship between marital satisfaction with five other components including emotional instability, return emotional, social maladjustment, close character and lack of independence. The results indicate a negative correlation between marital satisfaction and these items and t-student confirmed that there are meaningful relationship between marital satisfaction and emotional instability, return emotional, close character and lack of independence but there is no meaningful relationship between marital satisfaction and social maladjustment. In summary, the survey concluded that there is meaningful relationship between marital satisfaction and emotional maturity.
\end{abstract}

\section{Introduction}

Marriage is one of the most important events among young people in many countries especially those who live in traditional family oriented places and many young people consider a successful marriage as an extreme point of their lives. There are many studies to determine the important factors influencing long-term relationship between husband and wife (Stutzer \& Frey, 2006; Hawkins et al., 2008; Waller \& Peters, 2008). There are many studies on marital satisfaction and the influencing factors on this issue. Melton et al. (1995) discussed different parameters influencing a successful marriage. Anderson and Hamori (2000) discussed the most important factors signaling good quality marriage. Guzzo (2006) explained parameters on how marriage market conditions could affect entrance into cohabitation vs. marriage.

Donnellan et al. (2004) discussed some important issues called five big for sustainable marriage. They examined the relationship between the Big Five dimensions of personality and the marital

* Corresponding author. Tel: + 989131062110

E-mail addresses: es.mosavi@iaukhsh.ac.ir (S. E. Mosavi) 
relationships of over 400 couples and reported four major findings. These findings recommended that agreeableness and openness deserve increased attention as significant correlates of close relationships.

Asoodeh et al. (2010) explained factors for successful marriage and identified the factors of successful marriage, which accounts from self-described happy couples. They selected 300 couples from different companies, and the parents of students and performed their analysis using cluster sampling. The reported the most important factors for successful couples as trust and consultation, honesty, believe in God, make decisions together, strong commitment to each other, and friendly relationship. Traditional couples and non-traditional couples differed only in the procedures of family management.

Li and Fung (2011) presented a review process on facts and figures on marital satisfaction, which is gaining more concern in modern society. They reviewed dynamic goal theory of marital satisfaction to integrate previous findings about marital satisfaction. The theory argues that people have multiple goals to achieve in their marriage and concluded that these goals could be classified into three categories of personal growth, companionship and instrumental goals. The priority of the three types of marital goals is under dynamic changes across adulthood.

Young couples emphasize the personal growth goals, middle-aged couples prioritize the instrumental goals, while old couples concentrate on the companionship goals. The prioritized marital goals accomplished in marriage determine marital satisfaction. Other items influencing marital satisfaction are linked with marital goals in two ways. Some factors, such as life transitions and cultural values, affect the priority of different marital goals; while other factors, such as communication pattern, problem solving, and attribution facilitate the achievement of the prioritized marital goals.

Lopez et al. (2011) studied the effects of religious commitment and insecure attachment on marital satisfaction. They gathered data from newly married couples who did not have children and measured their religious commitment, adult attachment, and marital functioning. The results indicated that there was a small positive association between religious commitment and marital adjustment. Religious commitment buffered the negative relationship between attachment avoidance and marital adjustment. However, the results indicated a negative association between attachment anxiety and marital adjustment.

Glenn et al. (2010) implemented measures of marital success based on both marital survival and marital quality to assess how well first marriages entered at relatively late ages fare compared with those entered younger. Investigation of data from five American data sets revealed that the later marriages fare very well in survival but rather poorly in quality. The negative relationship beyond the early to mid-twenties between age at marriage and marital success is likely to be at least partially spurious. The findings recommended that most people have little or nothing to gain in the way of marital success by intentionally postponing marriage beyond the mid-twenties.

Oberlander et al. (2010) investigated various patterns of marital expectations and marriage among 181 urban, low-income, African American adolescent mothers and their mothers. They studied the effects of intergenerational marriage models and adolescent mother-grandmother relationship quality on marital expectations and marriage over the first seven years postpartum. At 24 months, half (52\%) of adolescent mothers anticipated to marry, but marital expectations did not predict marriage. Marital expectations were correlated with concurrent involvement in a romantic relationship, not intergenerational marriage models or a supportive adolescent mother-grandmother relationship.

After seven years, $14 \%$ of adolescent mothers were married. Married mothers lived in families characterized by the joint effects of intergenerational marriage models and supportive adolescent mother-grandmother relationships. They were older and had more children than did single mothers, recommending that they were in a family formation stage of life. 
In this paper, we study relationship between emotional maturity and marital satisfaction. The organization of this paper first presents details of sampling and questionnaire in section 2. Section 3 expresses the results of our study and concluding remarks are given in the last to summarize the contribution of the paper.

\section{Research framework}

The main hypothesis of this paper is to see whether there is meaningful relationship between emotional maturity and marital satisfaction. There are also five sub-hypothesis associated with the proposed study, which are as follows,

- There is a meaningful relationship between emotional instability and marital satisfaction.

- There is a meaningful relationship between return emotional and marital satisfaction.

- There is a meaningful relationship between social maladjustment and marital satisfaction.

- There is a meaningful relationship between close character and marital satisfaction.

- There is a meaningful relationship between lack of independence and marital satisfaction.

\subsection{Sample size}

The study covers all couples aged 25-35 who live in region 10 of the city of Esfahan, Iran, which contains 150 people. The Alpha ratio was calculated as 95\% but the correlation with social maladjustment is $47 \%$, lack of independence is $45 \%$, social maladjustment is $27 \%$, emotional stability is $18 \%$. Next, we present details of each five hypotheses using t-student statistics.

\section{The results}

In this section, we present details of our survey result. The first part of our survey is associated with the first hypothesis and Table 1 summarizes the results.

\section{Table 1}

Different statistics on relationship between emotional instability and marital satisfaction

\begin{tabular}{lccccccc}
\hline Variable & Number & Mean & Median & Mode & Standard deviation & Variance & Correlation \\
\hline Marital satisfaction & 120 & 78.72 & 80 & 72 & 13.73 & 188.60 & \multirow{2}{*}{0.186} \\
Emotional instability & 120 & 22.77 & 22 & 16 & 7.06 & 49.94 & \\
\hline
\end{tabular}

As we can observe from the results of Table 1, there is a negative correlation between emotional instability and marital satisfaction, which means we expect more marital satisfaction as emotional instability decreases. In addition, t-student for the hypothesis is as follows

$\left.t_{0}=\left|\frac{r \sqrt{n-2}}{\sqrt{1-r^{2}}}\right|>t_{\frac{a}{2}}(n-2), t_{0}=\left|\frac{(0.186) \sqrt{120-2}}{\sqrt{1-(0.186)^{2}}}\right|=2.167\right\rangle t_{0.05}(118)=1.96$

The result of t-student rejects the null hypothesis, which specifies there is a meaningful relationship between marital satisfaction and emotional instability when the significance level is five percent. Table 2 shows some statistics about the second hypothesis. 
Table 2

Different statistics on relationship between return emotional and marital satisfaction

\begin{tabular}{lccccccc}
\hline Variable & Number & Mean & Median & Mode & Standard deviation & Variance & Correlation \\
\hline Marital satisfaction & 120 & 78.72 & 80 & 72 & 13.73 & 188.60 & \multirow{2}{*}{0.287} \\
Return emotional & 120 & 22.79 & 22 & 14 & 7.27 & 52.88 & \\
\hline
\end{tabular}

As we can observe from the results of Table 2, there is a negative correlation between return emotional and marital satisfaction, which means we expect more marital satisfaction as return emotional decreases. The result of t-student, t-value=3.7, rejects the null hypothesis, which specifies there is a meaningful relationship between marital satisfaction and return emotional when the significance level is five percent. Table 3 shows some statistics about the third hypothesis.

Table 3

Different statistics on relationship between social maladjustment and marital satisfaction

\begin{tabular}{lccccccc}
\hline Variable & Number & Mean & Median & Mode & Standard deviation & Variance & Correlation \\
\hline Marital satisfaction & 120 & 78.72 & 80 & 72 & 13.73 & 188.60 & \multirow{2}{*}{0.091} \\
Social maladjustment & 120 & 22.79 & 18 & 16 & 4.89 & 23.92 & \multirow{2}{*}{. } \\
\hline
\end{tabular}

As we can observe from the results of Table 3, there is a negative correlation between social maladjustment and marital satisfaction, which means we expect more marital satisfaction as social maladjustment decreases. The result of t-student, $t$-value $=1$, cannot reject the null hypothesis and we cannot make a judgment on whether there is a relationship between marital satisfaction and social maladjustment when the significance level is five percent. Table 4 shows some statistics about the fourth hypothesis.

Table 4

Different statistics on relationship between close character and marital satisfaction

\begin{tabular}{lccccccc}
\hline Variable & Number & Mean & Median & Mode & Standard deviation & Variance & Correlation \\
\hline Marital satisfaction & 120 & 78.72 & 80 & 72 & 13.73 & 188.60 & \multirow{2}{*}{0.455} \\
Social maladjustment & 120 & 17.99 & 17 & 13 & 6.45 & 41.68 & \\
\hline
\end{tabular}

As we can observe from the results of Table 4, there is a negative correlation between close character and marital satisfaction, which means we expect more marital satisfaction as close character decreases. The result of t-student, $t$-value $=7.52$, rejects the null hypothesis, which specifies there is a meaningful relationship between marital satisfaction and close character when the significance level is five percent. Table 5 shows some statistics about the last hypothesis.

Table 5

Different statistics on relationship between lack of independence and marital satisfaction

\begin{tabular}{lccccccc}
\hline Variable & Number & Mean & Median & Mode & Standard deviation & Variance & Correlation \\
\hline Marital satisfaction & 120 & 78.72 & 80 & 72 & 13.73 & 188.60 & \multirow{2}{*}{0.186} \\
Social maladjustment & 120 & 18.03 & 18 & 17 & 3.54 & 12.60 & \\
\hline
\end{tabular}

As we can observe from the results of Table 5, there is a negative correlation between lack of independence and marital satisfaction, which means we expect more marital satisfaction as lack of independence decreases.

The result of t-student, t-value $=2.167$, rejects the null hypothesis, which specifies there is a meaningful relationship between marital satisfaction and lack of independence when the significance level is five percent. Finally, we present the results of our study for the main question of survey, which is summarized in Table 6. 
Table 6

Different statistics on relationship between emotional maturity and marital satisfaction

\begin{tabular}{lccccccc}
\hline Variable & Number & Mean & Median & Mode & Standard deviation & Variance & Correlation \\
\hline Marital satisfaction & 120 & 78.72 & 80 & 72 & 13.73 & 188.60 & \multirow{2}{*}{0.305} \\
Social maladjustment & 120 & 97.26 & 96 & 69 & 12.44 & 94.503 & \\
\hline
\end{tabular}

As we can observe from the results of Table 6, there is a negative correlation between emotional maturity and marital satisfaction, which means we expect more marital satisfaction as emotional maturity decreases. The result of t-student, $t$-value $=4.03$, rejects the null hypothesis, which specifies there is a meaningful relationship between marital satisfaction and emotional maturity when the significance level is either one or five percent.

\section{Conclusion}

In this paper, we have presented an empirical study to investigate the relationship between emotional maturity and marital satisfaction using a classical questionnaire. The proposed study split the main hypothesis into five detailed questions, which considers the relationship between marital satisfaction with five other components including emotional instability, return emotional, social maladjustment, close character and lack of independence. The results indicated a negative correlation between marital satisfaction and these items and t-student confirmed that there were meaningful relationship between marital satisfaction and emotional instability, return emotional, close character and lack of independence but there was no meaningful relationship between marital satisfaction and social maladjustment. In summary, the survey concluded that there is meaningful relationship between marital satisfaction and emotional maturity.

\section{Acknowledgment}

The authors would like to thank Islamic Azad University for their financial support on this project. The author also grateful for constructive comments received from the anonymous referees on earlier version of this working paper.

\section{References}

Anderson, D.A., \& Hamori, S. (2000). A theory of quality signaling in the marriage market. Japan and the World Economy, 12(3), 229-242.

Asoodeh, M.H., Khalili, S., Daneshpour, M., \& Lavasani, M.G. (2010). Factors of successful marriage: Accounts from self described happy couples. Procedia - Social and Behavioral Sciences, 5, 2042-2046.

Cronbach, L. J. (1951). Coefficient alpha and the internal structure of tests. Psychometrika, 16(3), 297-334.

Donnellan, N.B., Conger, R.D., \& Bryant, C.M. (2004). The Big Five and enduring marriages. Journal of Research in Personality, 38(5), 481-504.

Glenn, N.D., Uecker, J.E., \& Love Jr., R.W.B. (2010).Later first marriage and marital success. Social Science Research, 39(5), 787-800.

Guzzo, K.B. (2006). How do marriage market conditions affect entrance into cohabitation vs. marriage? Social Science Research, 35(2), 332-355.

Hawkins, A.J., Blanchard, V.L., Baldwin, S.A., \& Fawcett, E.B. (2008). Does marriage and relationship education work? A meta-analytic study. Journal of Consulting and Clinical Psychology, 76(5), 723-734.

Li, T., \& Fung, H.H. (2011). The dynamic goal theory of marital satisfaction. Review of General Psychology, 15(3), 246-254.

Likert, R. (1932). A Technique for the Measurement of Attitudes. Archives of Psychology, 140, 155. 
Lopez, J.L., Riggs, S.A., Pollard, S.E., \& Hook, J.N. (2011). Religious commitment, adult attachment, and marital adjustment in newly married couples. Journal of Family Psychology, 25(2), 301-309.

Melton, M.A., Hersen, M., Van Sickle, T.D., Van Hasselt, V.B. (1995). Parameters of marriage in older adults: A review of the literature. Clinical Psychology Review, 15(8), 891-904.

Oberlander, S.E., Miller Agostini, W.R., Houston, A.M., \& Black, M.M. (2010). A seven-year investigation of marital expectations and marriage among urban, low-income, African American adolescent mothers. Journal of Family Psychology, 24(1), 31-40.

Stutzer, A., \& Frey, B.S. (2006). Does marriage make people happy, or do happy people get married? Journal of Socio-Economics, 35(2), 326-347.

Waller, M.R., \& Peters, H. E. (2008). The risk of divorce as a barrier to marriage among parents of young children. Social Science Research, 37(4), 1188-1199. 